\title{
“Destruição da Arte Destrutiva” e constituição do sujeito
}

Andréa Vieira Zanella

\section{"Destruction of the Destructive Art" and constitution of the subject}


Resumo: Este artigo problematiza, a partir de uma nota de jornal que divulga um acontecimento em um museu londrino, a temática da identidade, tão cara às ciências humanas em geral e à psicologia em particular. Discute, a partir dos referenciais teóricos de L. S. Vygotski e M. Bakhtin/V. Voloshinov, a condição inexoravelmente dialógica das obras de arte, dos artistas e dos muitos outros que com estas obras se relacionam, o que caracteriza a dimensão relacional e sincrética do processo de constituição do sujeito.

Palavras-chave: Subjetividade. Constituição do sujeito. Identidade. Arte. Dialogia.

\begin{abstract}
This article discusses, from a newspaper notice about an event in a London museum, the theme of identity, so dear to the human sciences in general and psychology in particular. He discusses, from theoretical benchmarks of L. S. Vygotsky and M. Bakhtin / V. Voloshinov, the condition inexorably dialogic of art, artists and arts reader, which characterizes the syncretism and the relational condition of the subjectivity production.
\end{abstract}

Keywords: Subjectivity. Constitution of the Subject. Identity. Art. Dialogical.

ZANELLA, Andréa Vieira. "Destruição da Arte Destrutiva" e Constituição do Sujeito. Informática na Educação: teoria \& prática, Porto Alegre, v.10, n. 2, p.39-48, jul./dez. 2007. 
Lugar de lixo é no lixo. Foi o que pensou um funcionário da galeria Tate Britain, em Londres. Pensou e não titubeou: levou para a lixeira sacos de lixo pretos cheios de papelão e caixas vazias. Um pequeno detalhe: o que ele achou que deveria ser jogado no lixo era, na verdade, parte fundamental da instalação Reconstrução da primeira demonstração pública de arte destrutiva. Ao destruir a arte destrutiva, pode-se dizer que o funcionário usou o seu direito de crítica - um tanto destrutiva. O autor da instalação é o artista plástico alemão Gustav Metsger. (DESTRUÍRAM a arte..., 2004, p. 21 - itálico da própria revista).

A notíciamereceu uma pequena nota em revista semanal que circula por todo o território brasileiro, espaço provavelmente similar ao ocupado em outras revistas e jornais impressos ou eletrônicos em outros países. Oespaço que ocupou em mim, no entanto, foi maior, tanto é que guardei a página em que foi publicada e, provocada a escrever sobre o tema constituição do sujeito e arte para um projeto de coletâneaqueacabou não sendo concretizado, aresgatei do fundo de uma gaveta onde papéis vários repousamesquecidos. Comesse novo convite, retomei os escritos primeiros e teci a peça que aqui se apresenta.

Necessário um parêntesis: na verdade, o convite primeiro foi para escrever sobre "identidade", mas esse conceito incomoda, tanto quanto a nota do jornal. No caso da "identidade", o mal-estar é conhecido e já foi objeto de reflexões e críticas várias ${ }^{1}$, as quais compartilho. Palavra polissêmica, historicamente reconhecida como "qualidade do que é o mesmo", "qualidade do que é idêntico", "identidade" marca algo que nos faz unos e reconhecíveis. Algo da permanência, do que foi, do que é e será. Permanência? Unicidade? Núcleo fixo? Identidade? Háalgo que se mantémo mesmoemumarealidadequeéconstante movimento, queé processo, que se apresentacomo incessante vir a ser? Há fixidez nas flutuações incessantes dos espaços etempos?
Sobre o mundo concebemos esse inacabamentoeseumovimento incessante, eosavanços da física quântica e várias outras ciências não nos deixam cegar/calar para/sobre isso. No que se refere ao humano, no entanto, ainda se apresentam explicações para os modos de ser de cada pessoa assentadas em alguma essência, em uma suposta natureza, em algo dado, em algum núcleo identitário, fixo, a determinar modos de estar com outros. Para essas teorias, é reconhecida a "influência" do meio enquanto exterioridade a demarcar intensidades ou precisar o rumo do desenvolvimento do que emessênciajá está demarcado. No campo da arte, essas perspectivas essencialistas estão presentes nas afirmações dos dons, das vocações, na reiteração do dado, na produção e mitificação do artista e da obra dearte. Teorias que destituem dacondição relacional, dialógica e polifônica da realidade, do modo como estas são vividas e significadas por cada pessoa, o fundamento da produção de sei e das objetivações criadoras, inexoravelmente sociais².

Aquestão que se apresenta como desafioà inteligibilidade onde essas explicações se assentam é, portanto, não a da identidade, mas sim a da diferença e o modo como esta se produz, se apresentaeé(re)(des)conhecida. Odesafioéentendero complexo processo de produção dessa diferença, o movimentoemnosentretecemos, emquesomosproduzidos e produzimo-nos, nas relações com muitos outros, enquanto diferença.

Lev S. Vygotski, autor cuja obra é marcada pelo debate com os diferentes enfoques em psicologia que caracterizaram a sua emergência, ajuda a entenderesse aparente paradoxo ao afirmarque:

[...] toda a psique responde às características de um instrumento que seleciona, isola traços dos fenômenos. Um olho que tudo visse, precisamente por isto nada veria; uma consciência que se desse conta de tudo, não se daria conta de nada; se a introspecção tivesse consciência de tudo, não teria consciência de nada. Nossa consciência encon- 
tra-se encerrada entre dois limiares, vemos apenas um fragmento do mundo; nossos sentidos nos apresentam um mundo compendiado em extratos que são importantes para nós. (VYGOTSKI, 1996, p. 284).

Destaca-se neste excerto, para além de temáticas complexas que fogem ao escopo desse trabalho ${ }^{3}$, a dimensão ativa de toda e qualquer pessoa no processo de constituir-se enquanto tal, processo esse inexoravelmente social e histórico. Afinal, relacionamo-nos com a realidade, com os outros e com nós mesmos, a partir do modo como esses outros, presentes e ausentes, significam a realidade e, fundamentalmente, do modo como essas significações são ressignificadas por nós. Em outras palavras, isso quer dizer que toda e qualquer pessoa, que seus modos de ver/ouvir/sentir, são expressão e síntese das relações sociais das quais é parte/participa, tendo destaque nesse processo o modo como esses muitos outros nos afectam, como nos mobilizame como nos movemos a partir do modo comosomosmovidos.

Nesse sentido, épossível compreenderque, uma vez apropriados em sua significação, os signos mediadores da atividade caracterizam o psiquismo humano como semioticamente mediado e, em conseqüência, como inexoravelmente cultural ${ }^{4}$. A atividade humana, portanto, produz cultura e, no processo de sua própria produção, objetiva o ser humanoe ao mesmo tempo o subjetiva. Isso significa que o resultado da atividade é tanto a produção de uma realidade humanizada quanto a humanização do sujeito, posto a relação inexorável entre sujeito e sociedade, objetivação e subjetivação.

Aindaque brevemente, essas considerações iniciais contribuem para esclarecer o que entendo como o processo de constituição do sujeito, anunciado no título. Mas que relação estabeleço eu entrea nota da "destruição da arte destrutiva" e a temática constituição do sujeito, tão cara ao campo das ciências humanas e sociais e, em especial, à psicologia? Que possibilidades de sentido reconheço para oque se apresenta, aparentemente, sem sentido?

A resposta, de modo algum simples e direta, remete à reflexão sobre as relações que, naquele tempo e lugar-Londres, museu, 2004, Revista Isto É, público, leitor, autor(es) - instituíam lugares sociais específicos para os diferentes autores/personagens daquele contexto: o funcionário do museu, autor da destruição da arte destrutiva que virou notícia; o artista plástico, autor da arte que foi destruída; o público do museu; o jornalista, autor da nota que é apresentada como epígrafe; os editores da revista que autorizaram a sua publicação; os leitores vários, anônimos, que podem ou não ter se detido nas poucas linhas em que a "destruição da arte destrutiva" foi noticiada. Relações e lugares complexos, mutuamente constitutivos, demarcadores de (im)possibilidades várias de sentidos que se produzemetransformam no encontro de uns e outros, por vezes (in)tenso, quiçá fugaz.

Capturada pela nota da revista, provocome neste outro tempo e lugar a refletir sobre as perguntas que eu mesma formulei e apresentei em parágrafo anterior, visando percorrer alguns fios da trama que se apresenta como complexa, marcada por um movimento intenso que conota a questão da constituição do sujeito e de sua investigação, como uma tessitura plural. Plural como é a realidade, como se apresentam todos e qualquer um, posto que:

[...] cada coisa pode ser considerada como um microcosmo, como um modelo global em que se reflete todo o mundo... cada pessoa é em maior ou em menor grau o modelo da sociedade, ou melhor, da classe a que pertence, já que nela se reflete a totalidade das relações sociais. (VYGOTSKI, 1996, p. 368).

Somos, portanto, todos e cada um, expressão da sociedade da qual ativamente participamos, somos fios que sustentam a teia que, por sua vez, se apresenta como uma composição onde esses mesmos fios parecem sealojar. Alo- 
jar e sustentar, possibilidades supostamente antagônicas que levam à abertura de um parêntesis: a palavra "reflete", que Vygotski apresenta para explicitar a relação entre o microcosmo e o global, precisa ser compreendida em seu paradoxo, o que significa recusar o sentido de reflexo especular. Mas como eporque recusar?

Naverdade a recusa se assenta na compreensão de que toda e qualquer relação que estabelecemos comos outros, com a realidade ecomagente mesmo é uma relação semioticamente mediada (VYGOTSKI, 1992; PINO, 2000;ZANELLA, 2004). Os signos, social e historicamente produzidos, são osfundamentos dessas relações namedidaemque seapresentam como mediadores daatividade humana, como ferramentas psicológicas produzidas socialmente e particularmente apropriadas.

O reflexo, por sua vez, seja produzido na face de um espelho, em águas límpidas ou em uma superfície polida qualquer, jamais é substituto do que é ali refletido. Trata-se de uma imagem e, como tal, refere-se a alguma coisa ou em algum aspecto ao que se apresenta como uma realidade outra. Ou seja, reflexo é e não é, ao mesmo tempo, aquilo que se apresenta como realidade refletida, posto que todo e qualquer signo

[...] é não apenas um reflexo, uma sombra da realidade, mas também um fragmento material dessa realidade. Todo fenômeno que funciona como signo ideológico tem uma encarnação material, seja como som, como massa física, como cor, como movimento do corpo ou como outra coisa qualquer. (BAKHTIN; VOLOSHINOV, 1990, p. 33).

Refletir e refratar, portanto, consistem em um duplo e ao mesmo tempo único processo que se atualiza em cada momento social e histórico, em cada contexto onde pessoas, com a mediação de alguma forma de linguagem, seja oral, escrita, gestual, estabelecem interlocução. Interlocução, por sua vez, é atividade que se produz com um outro presente ou ausente, conhecido ou desconhecido, posto que remete à participação ativa dequalquerpessoa na produção de sentidos. Desse modo, destaca-se que o mediador-não intermédio, mas condição - da atividade não é o signo em si, mas o signo em sua significação, naquilo que diz às pessoas e a cada um em particular, ou seja, em seus sentidos, ao mesmo tempo reflexo e refração, realidade (re)inventada por cada pessoa que é, assim como os signos, ao mesmo tempo reflexo e refração do contexto e do momento histórico em que vive.

Destaco assim a complexidade da temática em questão, ou da questão tematizada, posto quea dimensão semiótica da atividade humana apresenta como axioma básico da singularidade a própria alteridade, encarnada em cada pessoa via significação de signos que são inexoravelmente sociais, ou seja, que trazem necessariamente as marcas dos sentidos que são, em cada contexto de enunciação, (re)inventados.

Toda e qualquer enunciação, por sua vez,

[...] é o produto da interação de dois indivíduos socialmente organizados e, mesmo que não haja um interlocutor real, este pode ser substituído pelo representante médio do grupo social ao qual pertence o locutor. A palavra dirige-se a um interlocutor: ela é função da pessoa desse interlocutor: variará se se tratar de uma pessoa do mesmo grupo social ou não, se esta for inferior ou superior na hierarquia social, se estiver ligada ao locutor por laços sociais mais ou menos estreitos. (pai, mãe, marido etc.). (BAKHTIN; VOLOSHINOV, 1990, p. 112).

Os sentidos, portanto, não estão nos signos em si, são produzidos em complexos contextos de enunciação, contextos onde se objetivam valores, preferências, interesses, necessidades, histórias coletivas e singulares, onde lugares sociais das pessoas em relação são reafirmados ou transformados. Compreender anota apresentada 
como epígrafe em sua relação com a temática constituição do sujeito requer, portanto, muito mais do que a simples decodificação das palavras, do que a tradução de significantes em significados. Énecessário um movimento que busque perscrutar alguns fios da trama de interesses, contextos, histórias, interlocuções e posições enunciativas que, nas palavras proferidas/escritas, se objetivam.

Afinal, como afirma Vygotski,

Para compreender a linguagem alheia nunca é suficiente compreender as palavras, é necessário compreender o pensamento do interlocutor. Mas inclusive a compreensão do pensamento, se não alcança o motivo, a causa da expressão do pensamento, é uma compreensão incompleta. Da mesma forma, a análise psicológica de qualquer expressão só está completa quando descobrimos o plano interno mais profundo e mais oculto do pensamento verbal, sua motivação. (1992, p. 343)

Depreende-se daí a complexidade das investigações que têm como foco a temática constituição do sujeito, pois requerem ao mesmo tempo o olhar para o sujeito, suas motivações, características singulares, trajetórias e condições de possibilidades, assim como para os muitos outros que se constituem como constantes parceiros de seus pensamentos, ações, discursos.

Toda palavra, segundo Bakhtin (1976) e Bakhtin e Voloshinov (1990), se origina de e necessariamente se dirige a um outro, presente ou ausente. A leitura da nota da revista, partindo desse pressuposto, se complexifica. Podemos pensar que o autor da nota simplesmente informa aos leitores um acontecimento, selecionado por ele dentre uma série de fatos que deixam de ser ali registrados. Leitores, portanto, são seus interlocutores, são alguns dos muitos outros para os quais seu discurso se destina e, ao mesmo tempo, se origina.
Masa escolha desse acontecimento, em particular, transformado em notícia a ser difundida, circulada, conhecida, significa que há também outros "outros" para quem o autor se dirige. Dentre vários possíveis, vou destacar como interlocutor potencial dessa nota as pessoas cujas produções artísticas são alçadas ao estatuto de obras de arte (os artistas), ou mesmo os críticos de arte e os curadores das mostras que, a partir do lugar social ${ }^{5}$ que ocupam, têm o poder de instituir o queéconsiderado arte eque, a partir de então, deverá ser considerado/consumido enquanto tal.

Oque diz na nota, o autor, a essas pessoas, concretas ou imaginárias? Entre muitos possíveis, salta aos olhos o sentido de que atribui ao faxineiro uma intencionalidade que caracteriza a ação de levar ao lixo o que assim Ihe parece. Afirma, no título da nota, que "lugar de lixo é no lixo", discurso que de certa forma podemos partilhar, posto um dos sentidos que a palavra lixo comporta em nossa culturado que é descartado, descartável, entulho, sem valor. Também podemos concordar que o faxineiro reconheceu, nos sacos plásticos amontoados em um determinado local cuja limpeza era de sua responsabilidade, algo que precisava ser dali removido.

Mas a continuidade da nota revela algo mais: ao afirmar que, "Ao destruir a arte destrutiva, podese dizer que o funcionário usou o seu direito de crítica-um tanto destrutiva", não estaria o autor atribuindo ao faxineiro intencionalidade que na verdade é sua? Não estaria exercendo o seu direito de crítica, embora não autorizado institucionalmente para tanto posto que não é reconhecido como crítico de arte?

É possível escutar nesse discurso do autor da notaque este fala aalguns outros, pela voz de um terceiro - o faxineiro, o que gostaria ele mesmo de poder dizer, mas cujo lugar social de não especialista em arte oblitera a possibilidade de escuta. A ironia da nota cabe bem aí, pois fala por ele um outro que 
provavelmente sequer pretende participardo debate, eque provavelmente continuará do mesmo alijado, a despeito de toda a polêmica que a sua ação provocou. Dondea estranheza naatribuição de uma crítica destrutiva auma ação motivada, muito provavelmente, pelo estrito senso de cumprimento do dever profissional: a limpeza do museu.

Motivos, palavras, pensamentos, pessoas, coletividades várias, diversas e dispersas... Tudo se relaciona com tudo, de forma direta ou não, em encontros e desencontros (im)previstos, ocasionais, aqui e acolá. Todos e cada um, nesse sentido, são tornados carne na historicidade da realidade social, são produtos dos e produtores de valores característicos do momento social e histórico em que vivem, bem como pelas histórias de vida, necessariamente singulares/coletivas. Desse modo, entende-se com Vygotski (2000) que, ao mesmo tempo em que cada pessoa é instituída pela cultura, é produtora de cultura, na medida em que estabelece relações (in)tensas com a realidade mediadas por sentidos vários. Os sentidos que à realidade, aos acontecimentos, ao que a cerca, atribui, são assim produto de motivações e afetos, estes também socialmente produzidos na teia cultural em que se subjetiva.

Voltemos ao museu e à "destruição da arte destrutiva". Museu, espaço (con)sagrado de exposição e de difusão cultural, pretensamente democrático assim como a própria sociedade, ícone por certo de uma determinada concepção de cultura - de uma cultura-valor, como ressaltam Guattari e Rolnik (1986), acessível a uma parcela da população, legitimada e legitimadora de um modo de estratificação social que se sustenta na demarcação de fronteiras.

Freqüentar o museu, por sua vez, não é garantia de acesso a essa produção cultural em sua dimensão discursiva, naquilo que os sentidos présupostos se propõem a provocar, tampouco de problematização das fronteiras que estratificam cul- turas e seus produtores, mesmo para quem por lá transita cotidianamente. Pode ser estranho, mas é isso que parece acontecer com o faxineiro que, ao limpar o local, "destrói a arte destrutiva”. Destrói, por certo, mas ofazao que parecenão intencionalmente, de modo algum como ação deliberada; não faz a crítica que o autor da nota a ele imputa, embora pareça tersuaação reconhecida pelo autor e provavelmente por muitos outros como a crítica que gostaria $(m)$ que tivesse sido feita. Disse assim o faxineiro ao não dizer o que um outro (e muitos outros) provavelmente diria $(\mathrm{m}) / \mathrm{faria}(\mathrm{m})$ : vai ao lixo a cultura-valor que para quem varre (e provavelmente muitos outros) não tem valoralgum.

Reconhece-se assim, com a "destruição da arte destrutiva", a destituição de um objeto estético em sua essencialidade, pois se revela com o movimento da vassoura a condição inexoravelmente social, histórica e plural de lugares, objetos, sujeitos, saberes e fazeres. Problematiza-se com a ação do faxineiro e a nota que a difunde, não a crítica em si a uma determinada produção cultural que está a ocupar contemporaneamente os espaços sagrados dos museus, mas a própria instituição de lugares, obras, autores, artistas, críticos, espectadores. Questiona-se a pretensa fixidez identitária descolada das condições de sua própria produção e o intenso movimento discursivo necessário para sua afirmação. Abalam-se os alicerces das fronteiras que, contra os movimentos incessantes que pulsam e violentam seus muros (in)visíveis, são alimentadas e insistem em se manter como condição para a hierarquia de possibilidades.

Por outro lado, com a "destruição da arte destrutiva" é possível problematizar também o fato dequepessoasque supostamentetêmacessoa produções culturais não necessariamente as acessam, ese ofazem nãoéde umaforma prescrita, pois significam o que vêem, ouvem, sentem, de um modo particular, a partir de suas possibilidades 
cognitivas, afetivas, éticas e estéticas, historicamente produzidas em condições sociais específicas.

Apresenta-se assim aquitambémaquestão da diferença: todos que estão no museu, lá estãoe e não estão, compartilham e não compartilham dos muitos possíveis sentidosque emergem dos/nossignos ali dispostos/dispersos, e ativamente produzem novos sentidos que lançam o que ali se apresentaa lugares e condições imprevistas. O faxineiro, mais especificamente, não reconheceu o lixo que não era lixo, os sacos plásticos amontoados recheados de papelão e jornal como signo outro: naquele lugar, o que é pode não ser, e o que não é, é alçado a um patamar outro pelo olhar do artista que ali o aloja, naquele templo da cultura, e também pelos olhares dos muitos outros que reconhecem e legitimam novos sentidos para o supostamente descartável. Artista, críticos de arte e expectadores, todos produtores e consumidores de sentidos que podem vir ou não a se objetivar em produtos que, por sua vez, podem vir a provocar a produção de novos sentidos, num incessante movimento de reinvenção da vidae de si mesmos. Sentidos apropriados não em si, mas em um intenso movimento de hibridização que caracteriza a cada sujeito como plural, sincrético ${ }^{6}$.

Em suma: ao varrer o lixo que não era lixo, o faxineiro provoca nos freqüentadores do museu e apreciadores (ou não) das artes contemporâneas, o desconcerto diante do inesperado, a destituição da obra de arte em sua essencialidade e a necessidade dequeestasejareconhecidacomofundamentalmente dialógica. Oautor da nota, por sua vez, ao atribuir ao faxineiro a "destruição da arte destrutiva", ao expressar pela voz de um outro a crítica que supostamenteapresentae que provavelmente muitos outros compartilham, revela a condição polifônica de todoe qualquerdiscurso.

Dessemodo, a notaapresentadacomo epílogo deste texto possibilita o reconhecimento de que tanto o artista quanto o faxineiro, o autor da nota, o crítico de arte, o público do museu, o leitor deste artigo e eu mesma que o escrevo, somos todos socialmente constituídos na trama em que várias vozes sociais se entrecruzam e dialogam (in)tensamente. Falamos em primeira pessoa por meio de palavras alheias tornadas próprias (BAKHTIN; VOLOSHINOV, 1990), assimcomo somos outros tomados uno. A nota critica, pois, mais do que a arte destrutiva, alógica que tende a separar, infrutiferamente, produções culturais e constituição das singularidades, uns e outros. Separados e unificados, apresentamo-nos ao mesmo tempo como identidade ediferença, como singularidade em permanente processo de vir a ser, o que leva a questionar e estranhar a postulação de algo que possa, na intrincada trama que concomitantemente institui o coletivo e o singular, ser apresentado como "qualidade do queéo mesmo".

Notas

1 Vários autores, de diferentes áreas do conhecimento, problematizam o conceito de identidade, como Canevacci (1996), Silva (2000), Maheirie (2002), entre outros.

${ }^{2}$ Vygotski ajuda a compreender essa condição social de toda e qualquer objetivação criadora quando afirma que "A arte é o social em nós, e, se o seu efeito se processa em um indivíduo isolado, isso não significa, de maneira nenhuma, que as suas raízes e essência sejam individuais" (VYGOTSKI, 1996, p. 315).

${ }^{3}$ Sobre a consciência na perspectiva vygotskiana, ver Aguiar (2000). Quanto à constituição social e histórica do olhar, ver Reis et al. (2004), Zanella (2006a, 2007).

${ }^{4}$ Sobre signos e mediação semiótica do psiquismo humano, ver Vygotski (2000); Pino (1995, 2000); Bakhtin e Voloshinov (1990); Zanella (2004, 2005, 2006b). 
${ }^{5} \mathrm{O}$ conceito de lugar social refere-se à posição assumida por cada pessoa na relação com outras e que institui modos de ser e estar. Essa posição é fundada e se sustenta nessas mesmas relações.

${ }^{6}$ Mássimo Canevacci, antropólogo, ao discutir as hibridizações culturais que caracterizam a realidade como sincrética, afirma essa mesma condição para toda e qualquer pessoa. Questiona a questão da identidade fixa de eu e destaca que "cachos do 'eu', entre si harmônicos ou em contraste, podem conviver dentro do mesmo sujeito" (CANEVACCI, 1996, p. 99). Embora não desenvolva essas argumentações, é possível encontrar consonâncias com as reflexões apresentadas neste texto.

\section{Referências}

AGUIAR, Wanda Maria Junqueira. Reflexões a partir a psicologia sócio-histórica sobre a categoria consciência. Cadernos de Pesquisa (Fundação Carlos Chagas), São Paulo, v. 110, p. 125-142, 2000.

BAKHTIN, Mikhail. Discurso na vida e discurso na arte. Tradução de Cristóvão Tezza. Nova York: Academic Press, 1976. Mimeografado.

BAKHTIN, Mikhail; VOLOSHINOV, Valentin N. Marxismo e filosofia da linguagem: problemas fundamentais do método sociológico na ciência da linguagem. São Paulo: Hucitec, 1990.

CANEVACCI, Massimo. Sincretismos: uma exploração das hibridizações culturais. São Paulo: Studio Nobel, 1996.

DESTRUÍRAM a arte autodestrutiva. Revista Isto É, São Paulo, n. 1822, p. 21, 08 set. 2004. Sessão A Semana.

GUATTARI, Felix; ROLNIK, Suely. Micropolítica: cartografias do desejo. Petrópolis: Vozes, 1986.

MAHEIRIE, Kátia. Constituição do sujeito, subjetividade e identidade. Interações, São Paulo, v. 7, n. 13, p. 31-44, 2002.

PINO, Angel. Semiótica e cognição na perspectiva histórico-cultural. Temas em Psicologia, Ribeirão Preto, n. 2, p. 31-40, 1995.

PINO, Angel. O social e o cultural na obra de Lev S. Vygotski. Educação \& Sociedade, Campinas, n. 71, p. 45-78, 2000.

REIS, Alice Casanova dos et al. Mediação Pedagógica: reflexões sobre o olhar estético em um contexto de escolarização formal. Psicologia: Reflexão e Crítica, Porto Alegre, v. 1, n. 17, p. 51-60, 2004.

SILVA, Tomaz Tadeu. (Org.). Identidade e diferença. Petrópolis: Vozes, 2000.

VYGOTSKI, Lev Semionovich. Obras Escogidas: problemas de psicología general. Madrid: Visor, 1992.

VYGOTSKI, Lev Semionovich. Teoria e método em Psicologia. São Paulo: Martins Fontes, 1996.

VYGOTSKI, Lev Semionovich. Manuscrito de 1929. Educação \& Sociedade, Campinas, v. 71, n. 21, p. 23-44, 2000.

ZANELLA, Andréa Vieira. Atividade, significação e constituição do sujeito: considerações à luz da psicologia histórico-cultural. Psicologia em Estudo, Maringá, v. 9, n. 1, p. 127-135, 2004.

ZANELLA, Andréa Vieira. Sujeito e alteridade: reflexões a partir da psicologia histórico-cultural. Psicologia \& Sociedade, Porto Alegre, v. 17, p. 99-104, 2005. 
ZANELLA, Andréa Vieira. Sobre olhos, olhares e seu processo de (re)produção. In: LENZI, Lúcia Helena Correa et al. (Orgs.). Imagem: intervenção e pesquisa. Florianópolis: Editora da UFSC, 2006a. p. 139-150.

ZANELLA, Andréa Vieira. "Pode até ser flor se flor parece a quem o diga": reflexões sobre educação estética e o processo de constituição do sujeito. In: ROS, Sílvia Zanatta Da; ZANELLA, Andréa Vieira; MAHEIRIE, Kátia (Orgs.). Relações estéticas, atividade criadora e imaginação: sujeitos e/em experiência. Florianópolis: Editora da UFSC, 2006b. p. 33-47.

ZANELLA, Andréa Vieira. Sobre olhares, fios e rendas: reflexões sobre o processo de constituição de educadores(as). In: ZANELLA, Andréa Vieira et al. (Orgs.). Educação Estética e constituição do sujeito: reflexões em curso. Florianópolis: Editora da UFSC, 2007. p. 143-154.

Recebido em agosto de 2007

Aceito para publicação em outubro de 2007

\section{Andréa Vieira Zanella}

Professora do Departamento e do Programa de PósGraduação em Psicologia da Universidade Federal de Santa Catarina.

Bolsista em Produtividade do Conselho Nacional de Desenvolvimento Científico e Tecnológico.

Doutora em Psicologia da Educação pela Pontifícia Universidade Católica de São Paulo. andreavz@pq.cnpq.br 